\title{
Commentary: Mitochondria are more than just the cells' powerhouse
}

\author{
Jakob Vinten-Johansen, PhD
}

\author{
From the Department of Surgery, Division of Cardiothoracic Surgery, Emory University, Atlanta, Ga. \\ Disclosures: Author has nothing to disclose with regard to commercial support. \\ Received for publication July 15, 2019; accepted for publication July 17, 2019; available ahead of print July 25, \\ 2019. \\ Address for reprints: Jakob Vinten-Johansen, PhD, 159 Montauk Ct, Clemmons, NC 27012 (E-mail: jvinten@ \\ emory.edu). \\ J Thorac Cardiovasc Surg 2020;160:e33-4 \\ 0022-5223/\$36.00 \\ Copyright (C) 2019 by The American Association for Thoracic Surgery \\ https://doi.org/10.1016/j.jtcvs.2019.07.029
}

Mitochondria are best known as the cells' powerhouse. However, mitochondria have a multitude of other vital functions including: (1) participating in fatty acid biosynthesis; (2) buffering intracellular calcium; (3) regulating immune responses; (4) triggering cell death by opening of the mitochondrial permeability transition pore; and (5) acting as the purported final effector in cell survival pathways that mitigate cell death. Salvaging mitochondria is, therefore, a perennial concern in cardioprotective strategies.

In this issue of The Journal of Thoracic and Cardiovascular Surgery, Guariento and colleagues ${ }^{1}$ test the hypothesis that intracoronary delivery of isolated autologous mitochondria before ischemia reduces infarct size and improves regional contractile function in the previously ischemic myocardium. To the authors' credit, the study was conducted in a large animal model of coronary artery occlusion-reperfusion using techniques with adequate resolution. The hypothesis is tenable, supported by previous studies $^{2}$ that have shown a reduction of necrosis and improvement of contractile function relevant to the present study. The study is largely observational, and does not offer insight on the dynamics of mitochondrial supplementation related specifically to in vivo intravascular delivery, but provides necessary empirical observations that drive further mechanistic studies.

The hypothesis that mitochondria can be internalized by cardiomyocytes when delivered by intravascular injection is, at first blush, surprising because external mitochondria must be taken up from the vascular compartment during a short transcoronary transit time, and then must be localized in an intracellular environment that supports their function. The authors have previously documented uptake after vascular delivery in small animal ex vivo models, ${ }^{3}$ and have also identified mechanisms of uptake by endocytosis, as well as intracellular trafficking to the native mitochondrial network in cell models. ${ }^{4}$ However, the 5- to 10-minute time frame referenced in the current article's discussion section might be inconsistent with a more rapid coronary

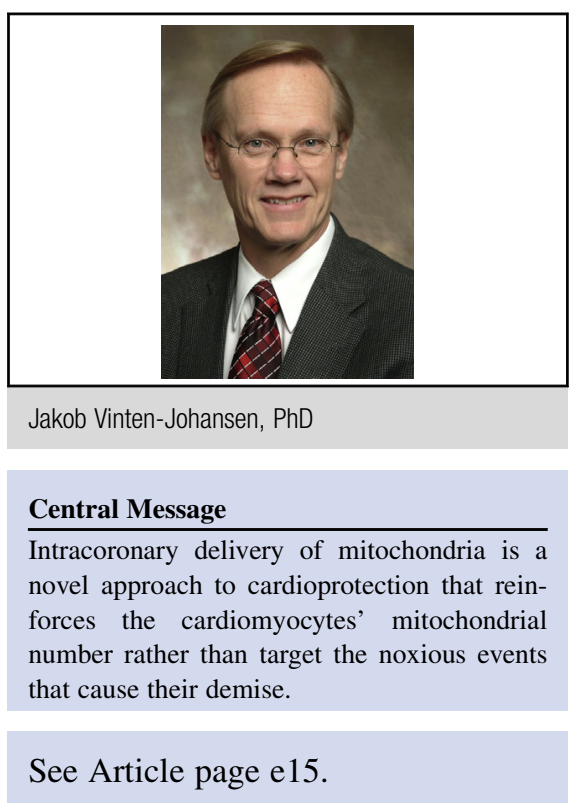

transit time. Reporting the intramyocardial mitochondrial population and uptake efficiency in the present study would have been helpful in supporting internalization with intravascular delivery.

The concept of mitochondrial supplementation is an innovative approach to cardioprotection. Rather than using drugs to interdict specific targets in ischemia-reperfusion injury, the approach supplements a victim of these noxious events (eg, reactive oxygen species, $\mathrm{Ca}^{2+}$ overload). However, there is a yin/yang to this approach. On the positive side, the mitochondrion is a critical target of therapy because of its vulnerability to injury and critical role in regulating cell survival. This approach also avoids the Achilles heel of pharmaceuticals with specific targets that render them ineffective by untargeted pathophysiological mechanisms that continue unabated. On the negative side, mitochondria are a distal rather than a proximal intervention point, so this approach does not address the causes of ischemia-reperfusion injury that thins the population of functional mitochondria. Perhaps mitochondrial supplementation can be combined with therapeutic agents that inhibit deleterious pathways in ischemia-reperfusion injury.

There are many questions raised by this innovative study, many of them mechanistic. But on a broader scale relevant to cardiac surgery, does mitochondrial transplantation show benefit in the surgical model of global myocardial ischemia (cross-clamp), hypothermia, and use of cardioplegia 
solutions? Will mitochondrial enhancement mitigate postsurgical stunning that has a different pathophysiology than necrosis or apoptosis? Will the additional resources needed to process isolated autologous mitochondria for use in cardiac surgery hamper clinical adoption? The answers to these and other questions will hopefully move the field toward clinical translation. Indeed, the recent limited clinical study ${ }^{5}$ showing efficacy of intramyocardially injected autologous mitochondria for rescue of pediatric patients receiving extracorporeal membrane oxygenation provides hope for such translation, but this needs to be tested for intravascular delivery as well.

\section{References}

1. Guariento A, Blitzer D, Doylamis I, et al. Pre-ischemic autologous mitochondrial transplantation by intracoronary injection for myocardial protection. J Thorac Cardiovasc Surg. 2020;160:e15-29.

2. McCully JD, Cowan DB, Emani SM, Del Nido PJ. Mitochondrial transplantation: from animal models to clinical use in humans. Mitochondrion. 2017;34: 127-34.

3. Cowan DB, Yao R, Akurathi V, Snay ER, Thedsanamoorthy JK, Zurakowski D, et al. Intracoronary delivery of mitochondria to the ischemic heart for cardioprotection. PLoS One. 2016;11:e0160889.

4. Cowan DB, Yao R, Thedsanamoorthy JK, Zurakowski D, Del Nido PJ, McCully JD. Transit and integration of extracellular mitochondria in human heart cells. Sci Rep. 2017;7:17450.

5. Emani SM, Piekarski BL, Harrild D, Del Nido PJ, McCully JD. Autologous mitochondrial transplantation for dysfunction after ischemia-reperfusion injury. J Thorac Cardiovasc Surg. 2017;154:286-9. 